\title{
Risk Evaluation of Non-lethal Weapon Procurement based on Comprehensive Fixed Weight-Variable Weight Model
}

\author{
Dong Chao, Wang Fang \\ Armed Police Engineering University, Xi'an 710086, China
}

\begin{abstract}
To make fixed weight confirmation more scientific and rational, this paper introduces entropy theory and improves original fixed weight - variable weight model based on fixed weight - variable weight model. This paper takes non-lethal weapon procurement for example, applies improved fixed weight variable weight model for risk evaluation and compares fixed weight - variable weight model before and after the improvement visually and clearly according to the chart. Risk evaluation results comply with actual situations. This paper provides reliable and important basis for risk management of non-lethal weapon procurement.
\end{abstract}

KEYWORD: non-lethal weapon procurement; risk evaluation; fixed weight - variable weight model

\section{INTRODUCTION}

Since 1990s, fighting against terrorism and transnational crime, stopping riot and safeguarding world peace have been common problems for the whole world. Gradually, our country has increased the outlay on non-lethal weapons procurement [1]. Faced with the huge outlay budget, reasonable, scientific and exact risk assessment is absolutely necessary. Fixed weight and variable weight model has been widely used in procurement risk evaluation and management decision, etc and weight assessment is based on subjective method, which leads to the subjectivity of decision-making [2]. This thesis integrates subjective and objective methods, which makes weight assessment and analysis of the result scientific and reasonable [3].

\subsection{Evaluation index system of procurement risk of non-lethal weapons}

Non-lethal weapons procurement differs from the common procurement like individual procurement, family procurement and enterprise procurement, etc. It has following features: (1) The publicity of capital source. The capital is from annual military expenditure. (2) The subject of the procurement. The aim is to make armed police force complete missions in duty, anti-terrorist and some other emergency successfully. (3) The particularity of the procurement. Non-lethal weapons refer to weapons and equipments can only make the living arms lose fighting ability but not kill them [4]. (4) The mobility of relevant office-holder. Job transfer of non-lethal weapons buyers will affect the duration of the procurement.

Table 1 Evaluation Index System of Procurement Risk of Nonlethal Weapons

\begin{tabular}{|c|c|c|}
\hline \multirow{5}{*}{$\begin{array}{l}\text { Procurement } \\
\text { risk of non- } \\
\text { lethal } \\
\text { weapons }(\mathrm{u})\end{array}$} & Cost risk $\left(\mathrm{u}_{1}\right)$ & $\begin{array}{l}\text { 1. Risk from improving } \\
\text { performance index }\left(\mathrm{u}_{11}\right) \text {; } \\
\text { 2. Risk from the uncertainty of } \\
\text { cost }\left(\mathrm{u}_{12}\right) \text {; } \\
\text { 3. Risk from bad care during } \\
\text { transportation }\left(\mathrm{u}_{13}\right) \text {. }\end{array}$ \\
\hline & $\begin{array}{l}\text { Personnel } \\
\text { risk }\left(\mathrm{u}_{2}\right)\end{array}$ & $\begin{array}{l}\text { 1. Risk from low personal quality } \\
\left(\mathrm{u}_{21}\right) \text {; } \\
\text { 2. Risk from interest demand of } \\
\text { the buyers }\left(\mathrm{u}_{22}\right) \text {; } \\
\text { 3. Risk from personal mobility } \\
\left(\mathrm{u}_{23}\right) \text {. }\end{array}$ \\
\hline & $\begin{array}{l}\text { Technology } \\
\text { risk }\left(\mathrm{u}_{3}\right)\end{array}$ & $\begin{array}{l}\text { 1. Risk from the complexity of } \\
\text { the procurement item system } \\
\left(\mathrm{u}_{31}\right) \text {; } \\
\text { 2. Risk from the innovation of the } \\
\text { procurement item system }\left(\mathrm{u}_{32}\right) \text {; } \\
\text { 3. Risk from bad technical } \\
\text { support }\left(\mathrm{u}_{33}\right) \text {. }\end{array}$ \\
\hline & $\begin{array}{l}\text { Environment } \\
\text { risk }\left(\mathrm{u}_{4}\right)\end{array}$ & $\begin{array}{l}\text { 1. Risk from natural environment } \\
\left(\mathrm{u}_{41}\right) \text {; } \\
\text { 2. Risk from social environment } \\
\left(\mathrm{u}_{42}\right) \text {. }\end{array}$ \\
\hline & $\begin{array}{l}\text { Guarantee } \\
\text { risk }\left(\mathrm{u}_{5}\right)\end{array}$ & $\begin{array}{l}\text { 1. Risk from management }\left(\mathrm{u}_{51}\right) \text {; } \\
\text { 2. Risk from supply }\left(\mathrm{u}_{52}\right) \text {; } \\
\text { 3. Confidentiality risk }\left(\mathrm{u}_{53}\right) \text {. }\end{array}$ \\
\hline
\end{tabular}




\section{WEIGHT ASSESSMENT OF THE EVALUATION INDEX OF PROCUREMENT RISK OF NON-LETHAL WEAPONS}

\subsection{Subjective methods to confirm the evaluation index weight value}

Use APH[5][6] to calculate the initial weight $W^{1}$ the evaluation index of procurement risk of nonlethal weapons. The following are methods:

(1)Establish a hierarchical structure model to analyze the connection and influence between nonlethal weapons risk factors and divide them into several hierarchies.

(2)Establish judgment matrix A The values in the matrix is determined by the $\mathrm{D}$-value of the average risk values. When $0 \leq \mathrm{D}$-value $\leq 10$, the number is 1 . When $10<\mathrm{D}$-value $\leq 20$, the number is 2 . The rest can be done in the same manner. When $\mathrm{D}$-value $<0$, the number is the reciprocal of absolute value of the Dvalue.

(3)Calculate weight vector quantity to get the maximum eigenvalue $\lambda_{\max }$.And calculate the corresponding feature vector $\mathrm{W}^{3}$

(4)Test the consistency of the matrix $C R=\frac{C I}{R I}$ $\left(C R=\frac{C I}{R I}\right), \mathrm{n}$ is the number of the hierarchy, RI is the consistency index of corresponding matrix.

(5)Based on the result of (3), calculate the synthetic weight $W^{1}$.

\subsection{Objective methods to confirm the index weight value}

Based on the processed matrix, calculate the entropy weight $W^{2}$ of the index. The uncertainty of relative importance degree of index $\mathrm{j}$ can be calculated by the following formula[7]:

$$
H\left(y_{j}\right)=-\sum_{i=1}^{n} \frac{y_{i j}}{y_{j}} \ln \frac{y_{i j}}{y_{j}},\left(y_{j}=\sum_{i=1}^{n} y_{i j}, \frac{y_{i j}}{y_{j}}<1\right)
$$

Based on the extremum property, standardize the formula:

$$
e\left(y_{j}\right)=\frac{H\left(y_{j}\right)}{\ln n}=-\frac{1}{\ln n} \sum_{i=1}^{n} \frac{y_{i j}}{y_{j}} \ln \frac{y_{i j}}{y_{j}}
$$

Based on $e\left(y_{j}\right)$ to calculate the evaluation weight of index $\mathrm{j} W_{j}^{2}$ :

$$
W_{j}^{2}=\frac{1-e\left(y_{j}\right)}{m-\sum_{i=1}^{m} e\left(y_{j}\right)}
$$

\subsection{Calculate the final fixed weight}

Plus the index weight of APH with the index weight of entropy method to get the fixed weight[8]

$$
W^{0}=\alpha W^{1}+(1-\alpha) W^{2}
$$

3 VARIABLE WEIGHT EVALUATION MODEL OF EVALUATION INDEX OF NON-LETHAL WEAPONS PROCUREMENT RISK

(1) The risk factor's value in different stage of nonlethal weapons procurement is

$$
R=\left\{R_{1}, R_{2}, \cdots, R_{m}\right\}
$$

(2) Calculate the weight of the bottom index relative to the aim $W^{0}=\left\{W_{1}^{0}, W_{2}^{0}, \cdots, W_{m}^{0}\right\}$

(3) According to the formula

$$
\begin{array}{r}
W_{i}(R)=W_{i}^{0} \times S_{i}(R) / \sum_{j=1}^{m} W_{J}^{0} S_{j}(R) \\
i=\{1,2 ; \cdot m,\}
\end{array}
$$

$$
S_{j}(R)=\left\{\begin{array}{c}
\left|e \times \frac{\left(b-R_{j}\right)}{b}\right|^{\frac{1}{m W_{j}^{0}}}+d \quad R_{j} \in(0, b] \\
d \quad R_{j} \in(b, c] \\
\left|\frac{R_{j}-c}{1-c}\right|^{\frac{1}{m W_{j}^{0}}}+d \quad R_{j} \in(c, 1]
\end{array}\right.
$$

$$
\left(\sum_{j=1}^{m} W_{j}(R)=1, \mathrm{j}=1,2, \ldots, \mathrm{m} ;\right) \quad \mathrm{b}, \mathrm{c}, \mathrm{d}, \mathrm{e}
$$
within $[0,1]$;

$\mathrm{b}$ is punishment level

$\mathrm{c}$ is motivation level

$\mathrm{d}$ is adjustment level

$\mathrm{e}$ is the range of motivation and punishment

\section{CASE ANALYSIS}

\subsection{Establish non-lethal weapons procurement risk evaluation index trends fixed weight}

(1) Use APH to calculate the subjective weights and ask relevant experts to evaluate it. Take 3 indexes for an example.

According to the experts marking, we can

$$
A=\left[\begin{array}{ccc}
1 & 1 / 3 & 1 / 3 \\
3 & 1 & 1 \\
3 & 1 & 1
\end{array}\right] \text { and figure out } \lambda_{\max }=3(C R<0.1),
$$

and figure out $W^{1}=(0.0448,0.1376,0.1376)$

(2) According to the entropy method formulas (1) (3), figure out $W^{2}=(0.0432,0.1033,0.1456)$

(3) Take $\alpha=0.5$ for an example. According to the formula (4), figure out $W^{0}=0.5 W^{1}+0.5 W^{2}=(0.0440,0.1205,0.1416)$. 


\subsection{Evaluation of non-lethal weapons procurement risk}

Given one risk factor value is $\mathrm{R}, \mathrm{b}=0.4, \mathrm{c}=0.7$, $\mathrm{d}=0.2$, $\mathrm{e}=0.8$, figure out the result according to the established evaluation system $(m=14)$ and fill them in Table 2.

Table 2 The value procurement risk evaluation of non-lethal weapons

\begin{tabular}{|c|c|c|c|c|c|c|c|c|c|c|c|c|c|c|}
\hline $\begin{array}{c}\text { Risk } \\
\text { factor }\end{array}$ & $u_{11}$ & $u_{12}$ & $u_{13}$ & $u_{21}$ & $u_{22}$ & $u_{23}$ & $u_{31}$ & $u_{32}$ & $u_{33}$ & $u_{41}$ & $u_{42}$ & $u_{51}$ & $u_{52}$ & $u_{53}$ \\
\hline $\mathrm{W}^{1}$ & 0.13 & 0.0936 & 0.0364 & 0.0429 & 0.0312 & 0.0559 & 0.0448 & 0.1376 & 0.1376 & 0.0432 & 0.0368 & 0.0861 & 0.0546 & 0.0693 \\
\hline $\mathrm{W}^{0}$ & 0.1403 & 0.0881 & 0.0421 & 0.0573 & 0.0278 & 0.0618 & 0.0440 & 0.1205 & 0.1416 & 0.0388 & 0.0271 & 0.1021 & 0.0513 & 0.0572 \\
\hline $\mathrm{R}$ & 0.716 & 0.4 & 0.43 & 0.426 & 0.416 & 0.391 & 0.408 & 0.451 & 0.546 & 0.776 & 0.45 & 0.512 & 0.375 & 0.755 \\
\hline $\mathrm{S}_{\mathrm{i}}^{1}(\mathrm{R})$ & 0.3998 & 0.2000 & 0.2000 & 0.2000 & 0.2000 & 0.2059 & 0.2000 & 0.2000 & 0.2000 & 0.3033 & 0.2000 & 0.2000 & 0.2199 & 0.3740 \\
\hline $\mathrm{S}_{\mathrm{i}}^{0}(\mathrm{R})$ & 0.4249 & 0.2000 & 0.2000 & 0.2000 & 0.2000 & 0.2096 & 0.2000 & 0.2000 & 0.2000 & 0.2798 & 0.2000 & 0.2000 & 0.2154 & 0.3202 \\
\hline $\mathrm{W}^{4}$ & 0.2131 & 0.0767 & 0.0298 & 0.0352 & 0.0256 & 0.0472 & 0.0367 & 0.1128 & 0.1128 & 0.0537 & 0.0302 & 0.0706 & 0.0492 & 0.1063 \\
\hline $\mathrm{W}$ & 0.2454 & 0.0725 & 0.0347 & 0.0472 & 0.0229 & 0.0533 & 0.0362 & 0.0992 & 0.1166 & 0.0447 & 0.0223 & 0.0841 & 0.0455 & 0.0754 \\
\hline
\end{tabular}

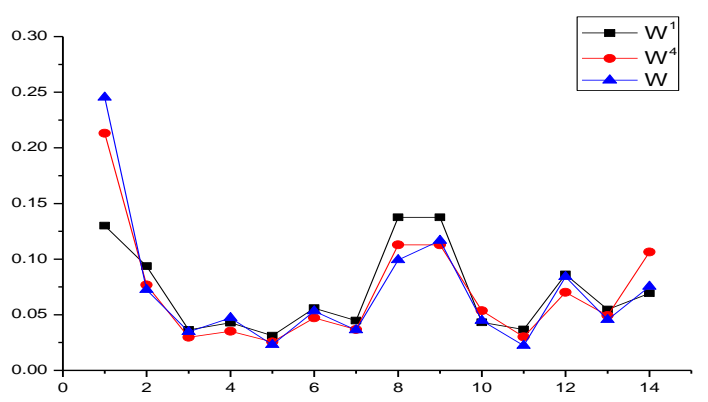

Figure 1 Comparison diagram before and after improvement

Take the 14 index of non-lethal weapons as abscissa and take the weight value before and after improvement as ordinate. Analyze the data as we can see in Figure 1, when the risk value $>0.7$, the weight value increase correspondingly. The improved model retains the advantages of punishment and motivation. Also, the diagram shows that weight model before improvement can not reflect same value's weight well. But the improved model can reflect the effects that risk values have on the weight very well. Thus it can be seen that the model can reflect the procurement risk of non-lethal weapons more scientifically, which can provide the decision- maker more reasonable basis.

\section{SUMMARY}

This thesis uses APH and entropy method to integrate subjective weights and objective weights so that weights assessment can be more scientific and reasonable. Meanwhile, based on relevant methods of combined weight theory, I established a non-lethal weapons procurement model and used this model to evaluate risk in non-lethal weapons procurement. I think the evaluation result has great guiding significance for non-lethal weapons procurement.

\section{REFERENCES}

[1] Thomas D. Waldhauser. Non-Lethal Weapon, Department of Defence non-lethal Weapon Program[EB/OL]. http://www.jnlwp.com,2009:26.

[2] Wang Wei, Military Weaponry Procurement Risk Analysis and Evaluation. Xi'an: Xi'an Technological University, 2010:30-43.

[3] Wang Kai, Tan Chao, Jin Jingfei, et al. Vague comprehensive assessment of scraper conveyer based on AHP and entropy weight method. Manufacturing Industry Automation, 2014:105-108.

[4] Zhao Shandong, Ma Yongzhong. Non-deadly weapons and Police equipment. Beijing: Ordnance Industry Press, 2005:3-10.

[5] Lv Bin, Li Xiaosong, Chen Qinghua. Equipment Procurement Risk Management Theory and Method. Beijing: National Defence Industry Press, 2011:144-153.

[6] Li Xiaosong, Li Xin, Chen Qinghua. Guided Missile Procurement Risk Dynamic State Vague Evaluation Model Research. Flechette and Guidance Academic Journal, 2011:177-184.

[7] Zhao Xinhao, Yao Anlin, Guo Lei, et al. Research on the Definition Method of Risk Factor Weight of Gas Transmission Station Based on AHP-Entropy Weight Method. China's Safety Production Science and Technology, 2012:91-96.

[8] Hou Lili, Xu Zhifan. Smart Power Grids Safety Evaluation Based on AHP-Entropy Weight Method. Modern Electric Power, 2012:85-89. 